\title{
Article \\ Microbial Production of Melanin Pigments from Caffeic Acid and L-Tyrosine Using Streptomyces glaucescens and FCS-ECH-Expressing Escherichia coli
}

\author{
Soo-Yeon Ahn ${ }^{1,+}$, Seyoung Jang ${ }^{2,+}{ }^{+}$Pamidimarri D. V. N. Sudheer ${ }^{3}$ and Kwon-Young Choi ${ }^{1,2,4, *}$ \\ 1 Environment Research Institute, Ajou University, Suwon 16499, Gyeonggi-do, Korea; sooyeon@ajou.ac.kr \\ 2 Department of Environmental and Safety Engineering, College of Engineering, Ajou University, \\ Suwon 16499, Gyeonggi-do, Korea; young0845@naver.com \\ 3 Amity Institute of Biotechnology, AMITY University Chhattisgarh, Raipur 493558, India; \\ pdvnsudheer@gmail.com \\ 4 Department of Environmental Engineering, College of Engineering, Ajou University, \\ Suwon 16499, Gyeonggi-do, Korea \\ * Correspondence: kychoi@ajou.ac.kr; Tel.: +82-31-219-1825 \\ + These authors contribute equally to this work.
}

Citation: Ahn, S.-Y.; Jang, S.; Sudheer, P.D.V.N.; Choi, K.-Y Microbial Production of Melanin Pigments from Caffeic Acid and L-Tyrosine Using Streptomyces glaucescens and FCS-ECH-Expressing Escherichia coli. Int. J. Mol. Sci. 2021, 22, 2413. https://doi.org/10.3390/ ijms22052413

Received: 13 January 2021

Accepted: 24 February 2021

Published: 27 February 2021

Publisher's Note: MDPI stays neutral with regard to jurisdictional claims in published maps and institutional affiliations.

Copyright: (c) 2021 by the authors. Licensee MDPI, Basel, Switzerland. This article is an open access article distributed under the terms and conditions of the Creative Commons Attribution (CC BY) license (https:// creativecommons.org/licenses/by/ $4.0 /)$.

\begin{abstract}
In this study, synthetic allomelanin was prepared from wild-type Streptomyces glaucescens and recombinant Escherichia coli BL21(DE3) strains. S. glaucescens could produce $125.25 \pm 6.01 \mathrm{mg} / \mathrm{L}$ of melanin with a supply of $5 \mathrm{mM}$ caffeic acid within $144 \mathrm{~h}$. The ABTS radical scavenging capacity of S. glaucescens melanin was determined to be approximately $7.89 \mathrm{mg} / \mathrm{mL}$ of $\mathrm{IC}_{50}$ value, which was comparable to L-tyrosine-based eumelanin. The isolated melanin was used in cotton fabric dyeing, and the effect of copper ions, laccase enzyme treatment, and the dyeing cycle on dyeing performance was investigated. Interestingly, dyeing fastness was greatly improved upon treatment with the laccase enzyme during the cotton dyeing process. Besides, the supply of C5-diamine, which was reported to lead to more complex crosslinking between melanin units, to caffeic acid-based melanin synthesis was also investigated for higher production and novel functionalities. To facilitate the supply of caffeic acid and C5-diamine, E. coli strains expressing each or combinations of tyrosine ammonia lyase/ $p$-coumarate 3-hydroxylase, feruloyl-CoA synthetase/enoyl-CoA hydratase/aldolase, and tyrosinase/lysine decarboxylase enzymes were prepared and investigated for their eumelanin, C5diamine, and allomelanin production from L-tyrosine and L-lysine, respectively. Finally, H-NMR, FT-IR, and MALDI-TOF analysis of the synthetic melanin pigments were attempted to obtain the chemical information.
\end{abstract}

Keywords: eumelanin; allomelanin; melanin-diamine complex; caffeic acid; L-lysine; L-tyrosine

\section{Introduction}

Melanin is one of the most well-known and abundant pigments in nature. The biological function and structure of melanin vary depending on the species, and it generally forms brown and black pigments [1-3]. Depending on the type of substrate used for its biosynthesis and synthetic route, melanin pigments can be classified into several groups. In general, dihydroxyphenylalanine (L-DOPA) and L-dopaquinone-based melanin are classified into eumelanin. And allomelanin, which are composed of aromatic monomers with a catechol structure such as caffeic acid and pyomelanin, have also been reported $[4,5]$. Melanin pigments have a complex structure with varying repeating units that are randomly polymerized. These units include L-DOPA, dopaquinone, dopachrome, and 5,6dihydroxyinodole which were generated through the tyrosinase dependent L-tyrosine conversion in eumelanin synthesis $[1,6]$.

Several melanin-producing strains have been reported. For example, bacteria such as Streptomyces glaucescens, Nocardiopsis alba, Pseudomonas stutzeri, and fungi such as Armil- 
laria ostoyae, Aspergillus funigatus, and Daldinia concentrica have been reported to produce L-DOPA-based eumelanin [7-13]. Their melanin production titers were reported to range from a few to many $\mathrm{g} / \mathrm{L}$, and some showed excellent titers. Not only wild-type based melanin production, but also a recombinant strain expressing enzymes in melanin synthetic pathway were often reported. Recently, the MelC enzyme, a type of tyrosinase derived from Bacillus megaterium, was identified, and was utilized for the biosynthesis of eumelanin in Escherichia coli [14-16]. Besides, recombinant allomelanin biosynthesis has been reported through generating monomers having a catechol structure derived from caffeic acid and protocatechualdehyde [17]. Recently, Jang et al. reported the allomelanin production with $0.2 \mathrm{~g} / \mathrm{L}$ of titer by constructing feruloyl-CoA synthetase (FCS) and enoyl-CoA hydratase/aldolase (ECH) expression system in E. coli which could bioconvert caffeic acid into allomleanin repeating unit of protocatechualdehyde [18]. Also, heterologous expression of 4-hydroxyphenyl pyruvate dioxygenase (HPPD) in E. coli to synthesize homogentisate from L-tyrosine was reported to result in $0.315 \mathrm{~g} / \mathrm{L}$ of pyomelanin production [19].

Along with melanin production using microbial, application of melanin pigments has been greatly attempted. Melanin extracts from natural and synthetic sources, for example, have been utilized as UV-protective films and coating materials owing to their excellent physical and biological functionalities. Recently, an attempt to design and engineer the physiological functionalities of melanin by introducing new radical precursors into melanin synthetic pathways has been reported. For example, 3-hydroxyindole was introduced by expressing a cytochrome $\mathrm{P} 450$ monooxygenase (CYP) enzyme that mediates a site-specific hydroxylation reaction to indole $\mathrm{C} 3$ position in eumelanin biosynthesis, and the generated novel melanin showed different physical functionalities [20]. Also, electrochemical properties of synthetic melanin have been reported to widen the sphere of its application to the field of electrochemistry [21-23]. Besides, it could also be used for pharmaceutical and cosmetic materials owing to its high biocompatibility [24-26].

Such an attempt to engineer the functionality of synthetic melanin, in this study, novel melanin pigments were synthesized and applied for fabric dyeing. First, wild-type S. glaucescens melanin was investigated for melanin production. Cells were cultured in a medium containing caffeic acid to biotransform caffeic acid into allomelanin. The generated melanin was isolated and used for cotton fabric dyeing. After washing the melanin-dyed fibers, the dyeing fastness was determined through a color difference test. The fastness was investigated against several dyeing conditions such as copper ions addition, multi-dyeing cycles, and laccase enzyme treatment.

Next, recombinant strains were constructed to establish a system capable of simultaneously producing eumelanin and allomelanin in E. coli host cells and to engineer the structural properties of repeating units. To facilitate this, a system capable of supplying C5-diamine (cadaverine) or generating it from L-lysine was attempted to introduce cross-link reagent in melanin synthesis. Eumelanin was supplied from L-tyrosine through the MelC reaction, and protocatechualdehyde-based allomelanin was supplied from Ltyrosine through the simultaneous enzymatic reaction of tyrosine ammonia-lyase (TAL) and $p$-coumarate 3-hydroxylase $(\mathrm{C} 3 \mathrm{H})$. Also, the crosslinking reagent of $\mathrm{C} 5$-diamine was supplied from L-lysine through the enzymatic reaction of lysine decarboxylase (CadA) [27]. A system capable of producing melanin-diamine complexes in a single whole cell reaction was constructed investigated for its melanin production. Finally, structural understandings of the synthesized melanin pigments were attempted by H-NMR and FT-IR analysis. The results of this study were expected to contribute to future research on functional polymers and fibers containing microbial melanin and the development of a platform strain capable of synthesizing new functional melanin.

\section{Results}

\subsection{S. glaucescens Culture and Caffeic Acid-Based Melanin Production}

Previously bioproduction of melanin using $S$. glaucescens from protease peptone was reported to result in $350 \mathrm{mg}$ dry wt/L of titer [7]. This suggested microbes could be 
used as a conversion toolbox for melanin pigment production. To facilitate this, wildtype S. glaucescens and recombinant E. coli strains were investigated for caffeic acid-based melanin synthesis with the supplementation of C5-diamine (Figure 1A). First, caffeic acid-based allomelanin was produced through $S$. glaucescens whole-cell biotransformation. S. glaucescens was cultured at $30^{\circ} \mathrm{C}$ for 5 days, and $5 \mathrm{mM}$ caffeic acid was added to the culture solution for biotransformation. Cells grew to an $\mathrm{OD}_{600}$ of 0.26 for $142 \mathrm{~h}$ and a dry weight of $0.17 \mathrm{mg} / \mathrm{L}$ could be obtained (Figure 1B). To measure the amount of melanin produced, $1 \mathrm{~mL}$ of each sample was collected every $24 \mathrm{~h}$ and quantitatively analyzed. Melanin production increased rapidly between $24 \mathrm{~h}$ and $72 \mathrm{~h}$ during biotransformation, and the highest titer of $125.25 \pm 6.01 \mathrm{mg} / \mathrm{L}$ could be achieved at $144 \mathrm{~h}$ (Figure 1C). Based on the caffeic acid fed to the medium, the final yield was calculated as $0.14 \mathrm{~g}$ melanin $/ \mathrm{g}$ caffeic acid.

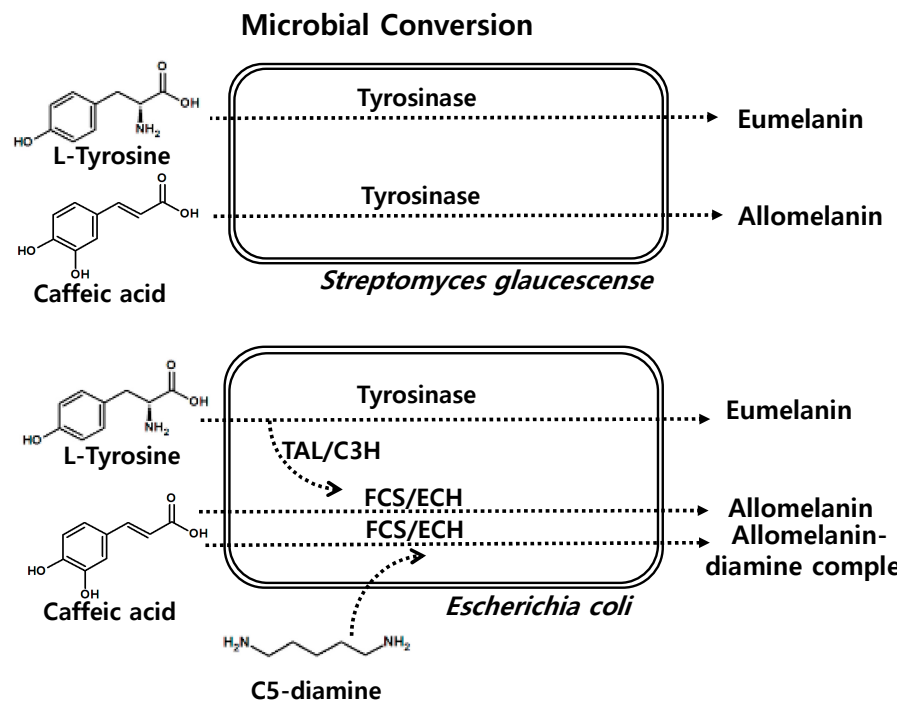

(A)

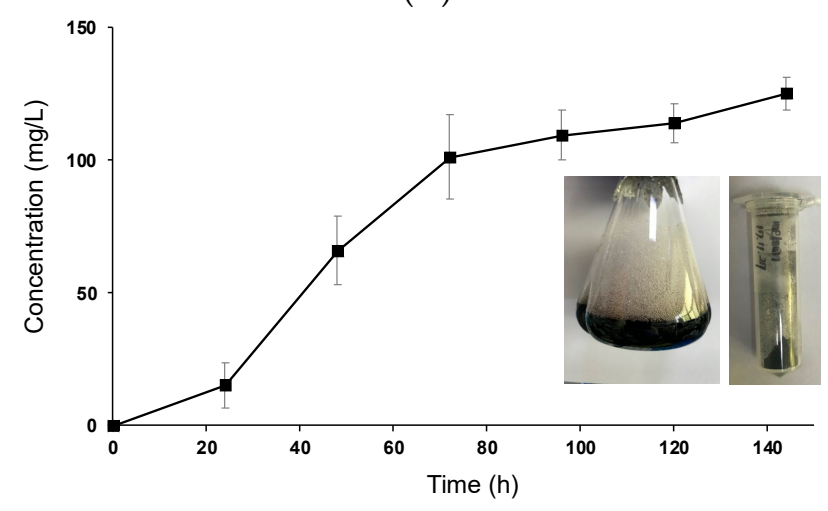

(C)

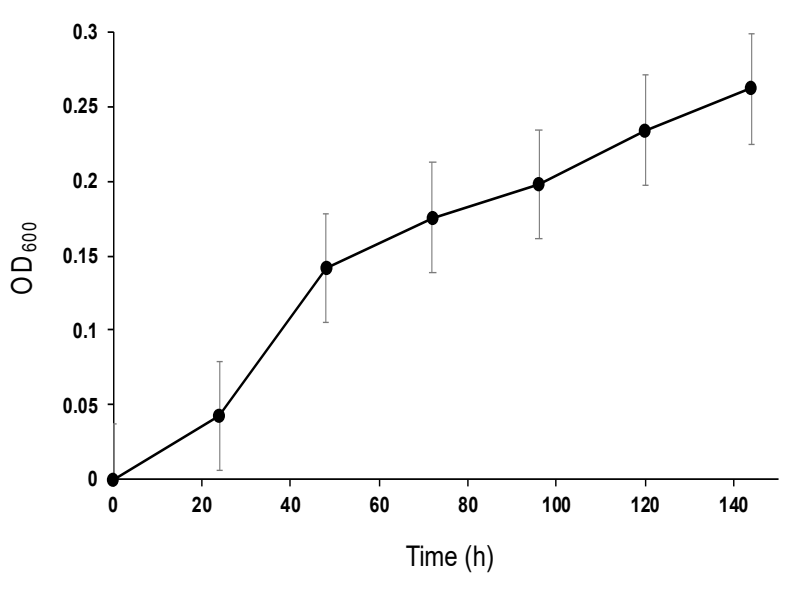

(B)

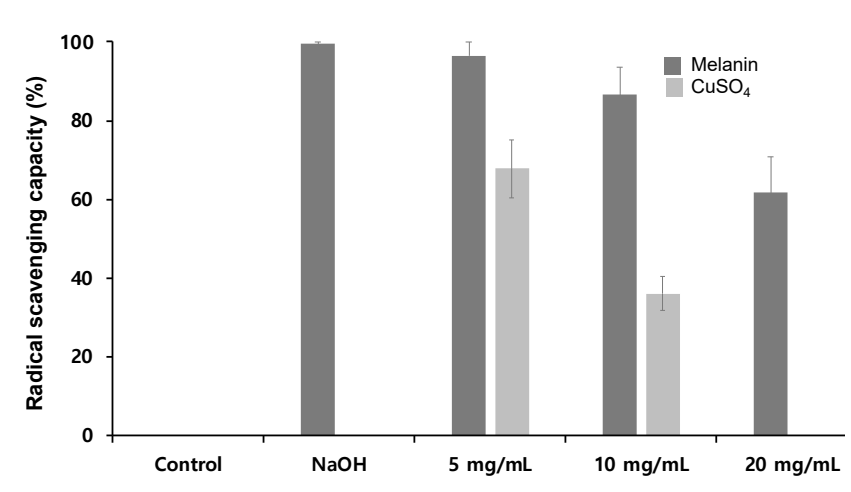

(D)

Figure 1. (A) Microbial conversion of L-tyrosine and caffeic acid by Streptomyces glaucescens and engineered E. coli. To prepare the microbial melanin pigments, $5 \mathrm{mM}$ of caffeic acid was supplied to the culture medium and the isolated melanin pigment was dried for further experiments. (B) Time-dependent growth curve of S. glaucescens. (C) Time-dependent production of caffeic acid-based melanin. The highest melanin production titer was achieved at $125.25 \pm 6.01 \mathrm{mg} / \mathrm{L}$ at $144 \mathrm{~h}$ of incubation. (D) Determination of radical scavenging capacity of melanin. 


\subsection{ABTS Radical Scavenging Capacity of Caffeic Acid-Based Melanin}

Melanin pigment has been shown to have antioxidant properties [7,28-31]. In particular, eumelanin synthesized through L-tyrosine biotransformation in E. coli has been reported to exhibit antioxidant efficacy at an $\mathrm{IC}_{50}$ level of $200-300 \mu \mathrm{g} / \mathrm{mL}$, while homogentisatebased pyomelanin from L-tyrosine had an $\mathrm{IC}_{50}$ level of approximately $100 \mu \mathrm{g} / \mathrm{mL}[7,17]$. In this study, the ABTS radical removal capacity of S. glaucescens melanin was determined as an $\mathrm{IC}_{50}$ value of $25.08 \mathrm{mg} / \mathrm{mL}$ and $7.89 \mathrm{mg} / \mathrm{mL}$ in the presence of copper ions (Figure 1D). These were 10 and 4 times higher than those of eumelanin and pyomelanin in the absence of copper ions, respectively.

\subsection{Dyeing Performance and Fastness of Synthetic Melanin on Cotton}

S. glaucescens melanin was applied for cotton dyeing and use as functional fibers. The manufacture of functional cotton materials dyed with melanin was conducted based on the results of the evaluation of the cotton fiber dyeing performance of previously reported indigo-based dyes [20]. A $10 \mathrm{~cm} \times 10 \mathrm{~cm}$ cotton sheet was prepared and stained with the melanin culture supernatant first. The dyeing was carried out at different reaction conditions with heating at $50{ }^{\circ} \mathrm{C}$ for $2 \mathrm{~h}$ (Figure 2A). The dyeing performance of cotton, which was visually checked immediately after dyeing and drying, was found to be the lowest in cotton 3 , in which copper ions were added during dyeing. To quantitatively evaluate the dyeing performance, color differences with specific values were determined (Table 1). In particular, the $L$ value representing the brightness was quantitatively compared for each of the stained cotton sheets (1-6), and a darker color was displayed numerically. The addition of copper ions to the cotton without any treatment in the melanin supernatant during the dyeing process showed the lowest L value (\#2 in Figure 2A), suggesting the highest dyeing performance.

\begin{tabular}{c|c|c|c|c|c|c}
\hline $\begin{array}{c}\text { Dyeing } \\
\text { experiments }\end{array}$ & 1 & 2 & 3 & 4 & 5 & 6 \\
\hline $\mathrm{Cu}^{2+}$ in medium & & $1 \mathrm{mg}$ & & & & \\
\hline $\mathrm{Cu}^{2+}$ in dyeing & & & $1 \mathrm{mg}$ & & & \\
\hline Dyeing cycle & $\times 1$ & $\times 1$ & $\times 1$ & $\times 1$ & $\times 2$ & $\times 2$ \\
\hline Laccase & & & & $3 \mathrm{mg}$ & & $3 \mathrm{mg}$ \\
\hline Before washing \\
After washing
\end{tabular}

(A)

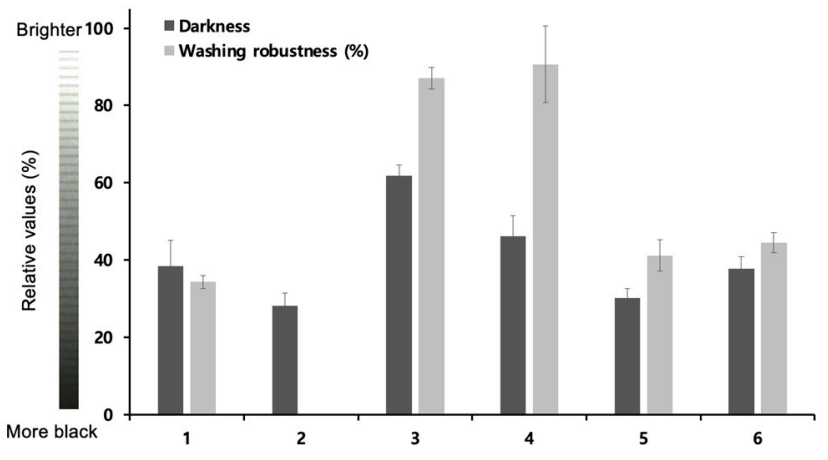

(B)

Figure 2. (A) Dyeing of S. glaucescens melanin on cotton fabric at different conditions: (1) dyeing with the culture supernatant without copper ions, (2) dyeing with the culture supernatant where melanin was synthesized by adding copper ions to the culture solution, (3) copper ions added to the melanin supernatant during dyeing process, (4) $3 \mathrm{mg}$ (1.5 U) of laccase enzyme treatment to the melanin supernatant during dyeing, (5) double dyeing cycles without copper and laccase enzyme treatment and (6) $3 \mathrm{mg}$ (1.5 U) of laccase enzyme treatment during dyeing and the double dyeing cycles. (B) Dyeing performances and dyeing fastness of caffeic acid-based melanin on cotton fabric. The dyeing performance was measured based on the brightness of $\mathrm{L}$ in Table 1 , and the dyeing fastness was determined through the equation: $100+\left[\left(\mathrm{L}+\mathrm{L}^{\prime}\right) / \mathrm{L}\right] \times 100(\%)$, where $\mathrm{L}$ is the brightness before washing and $\mathrm{L}^{\prime}$ is the brightness after washing. 
Table 1. Color differences of S. glaucescens melanin-dyed cotton samples.

\begin{tabular}{|c|c|c|c|c|c|c|}
\hline \multicolumn{2}{|c|}{ Cotton Samples } & \multirow[b]{2}{*}{$38.45+6.64$} & $a^{2}$ & $\mathbf{b}^{3}$ & $\Delta \mathrm{E}$ & \multirow{2}{*}{$\begin{array}{c}\begin{array}{c}\text { Washing } \\
\text { Robustness (\%) }\end{array} \\
\mathrm{ND}^{4}\end{array}$} \\
\hline & 1 & & $0.97 \pm 0.43$ & $6.96 \pm 0.93$ & $39.08 \pm 6.69$ & \\
\hline & 2 & $28.12 \pm 3.37$ & $0.31 \pm 0.23$ & $6.93 \pm 0.53$ & $28.96 \pm 3.39$ & ND \\
\hline Before & 3 & $61.77 \pm 2.73$ & $-0.75 \pm 0.28$ & $14.67 \pm 0.25$ & $63.50 \pm 2.60$ & ND \\
\hline \multirow[t]{5}{*}{ washing } & 4 & $46.13 \pm 5.37$ & $-0.83 \pm 0.63$ & $10.19 \pm 0.44$ & $47.26 \pm 5.16$ & ND \\
\hline & 5 & $30.15 \pm 2.45$ & $-1.02 \pm 0.05$ & $8.06 \pm 0.02$ & $31.23 \pm 2.36$ & ND \\
\hline & 6 & $37.71 \pm 3.15$ & $0.54 \pm 0.02$ & $11.59 \pm 0.06$ & $39.46 \pm 2.99$ & ND \\
\hline & 1 & $63.71 \pm 1.74$ & $0.72 \pm 0.81$ & $3.34 \pm 0.19$ & $63.80 \pm 1.74$ & 34.3 \\
\hline & 2 & $67.05 \pm 0.26$ & $-1.12 \pm 0.04$ & $4.05 \pm 0.11$ & $67.18 \pm 0.25$ & 0 \\
\hline After & 3 & $69.81 \pm 2.79$ & $-0.94 \pm 0.23$ & $8.19 \pm 0.22$ & $70.29 \pm 2.75$ & 87.0 \\
\hline \multirow[t]{3}{*}{ washing } & 4 & $50.44 \pm 9.87$ & $-0.96 \pm 0.04$ & $8.71 \pm 0.18$ & $51.21 \pm 9.69$ & 90.7 \\
\hline & 5 & $47.90 \pm 4.06$ & $0.17 \pm 0.35$ & $6.67 \pm 0.03$ & $48.36 \pm 4.02$ & 41.1 \\
\hline & 6 & $58.64 \pm 2.57$ & $-0.02 \pm 0.36$ & $7.00 \pm 0.04$ & $59.05 \pm 2.55$ & 44.5 \\
\hline
\end{tabular}

$\mathrm{L}^{1}$ : brightness, $\mathrm{a}^{2}$ : the closer to + , the redder, the closer to - , the more green; $\mathrm{b}^{3}$ : the closer to + , the more yellow, the closer to - , the bluer. $\Delta E_{\mathrm{ab}}^{*}=\left[\left(\Delta L^{*}\right)^{2}+\left(\Delta a^{*}\right)^{2}+\left(\Delta b^{*}\right)^{2}\right]^{\frac{1}{2}} \cdot \mathrm{ND}^{4}:$ not determined.

Next, each of the dyed cotton samples was washed with distilled water to measure the dyeing fastness before and after washing (Figure 2B, bright bars). Fastness was reported as a percentage by quantifying the $\mathrm{L}$ value before and after washing according to the equation: $100+\left[\left(\mathrm{L}-\mathrm{L}^{\prime}\right) / \mathrm{L}\right] \times 100(\%),\left(\mathrm{L} ;\right.$ before washing, $\mathrm{L}^{\prime}$; after washing). Not only did the $\mathrm{L}$ value show a distinct distribution depending on the dyeing process, but the fastness also showed a deviation of up to $80 \%$ or less than $40 \%$. Interestingly, laccase enzyme treatment during the dyeing process greatly increased the robustness of cotton 4 (90.6\%). Laccase enzyme treatment might induce radical formation in the melanin structure, leading to the tighter binding of melanin to the cellulose constituting the cotton fiber tissue. According to previous reports of laccase-mediated oxidation of DOPA for coloration of silk fabric, the addition of laccase could catalyze the oxidation of melanin and enhance its polymerization, followed by coloration [32-34]. When copper ions were added during dyeing, the color fastness was $86.9 \%$. In other cases, there was no significant difference in fastness. However, when copper ions were added during culture, both dyeing performance and fastness were low.

\subsection{Caffeic Acid Melanin Complex Production}

According to a recently published paper, the addition of C6-diamine (hexamethylenediamine) to caffeic acid can induce cross-linking to form a film [35]. Based on previous results where caffeic acid-based allomelanin was produced using wild type S. glaucescens, engineered allomelanin biosynthesis in a recombinant $E$. coli system was attempted. Two enzymatic reactions (FCS and ECH) were introduced in an E. coli host to convert the carboxylic acid functional groups into aldehyde as the aldehyde functional group can undergo reductive amination with diamine cross-linkers, which could form allomelanin-diamine complexes (Figure 3A). The host cells expressing genes encoding FCS and ECH were incubated with a co-supply of caffeic acid and C5-diamine. The cells could produce allomelanin-diamine complexes up to $0.251 \mathrm{~g} / \mathrm{L}$ in $12 \mathrm{~h}$ (Figure 3B). This was a $25 \%$ increase compared to the production of $0.2 \mathrm{~g} / \mathrm{L}$ of allomelanin in the absence of diamine [18]. Based on the substrate fed to the medium, a final yield of $0.178 \mathrm{~g}$ of melanin/g substrate could be obtained. 


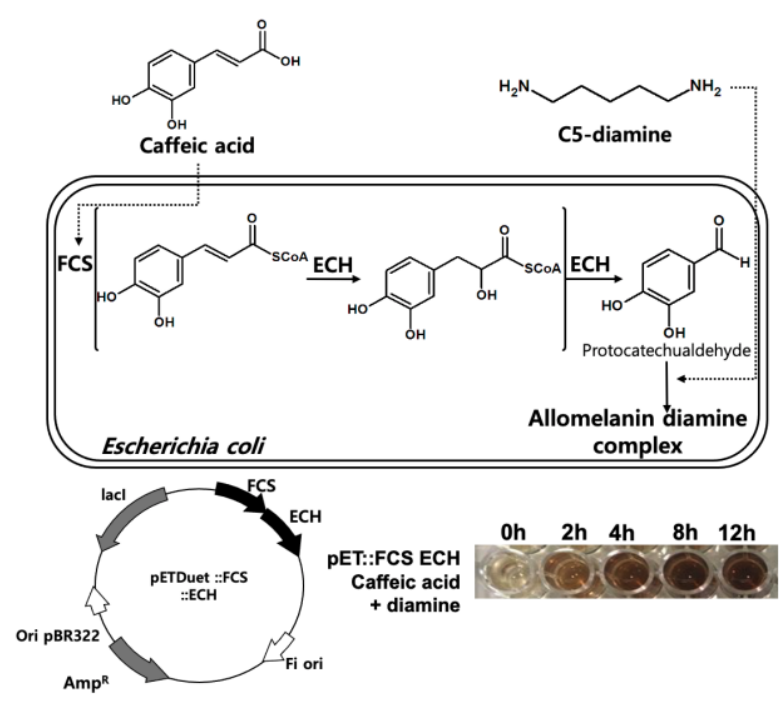

(A)

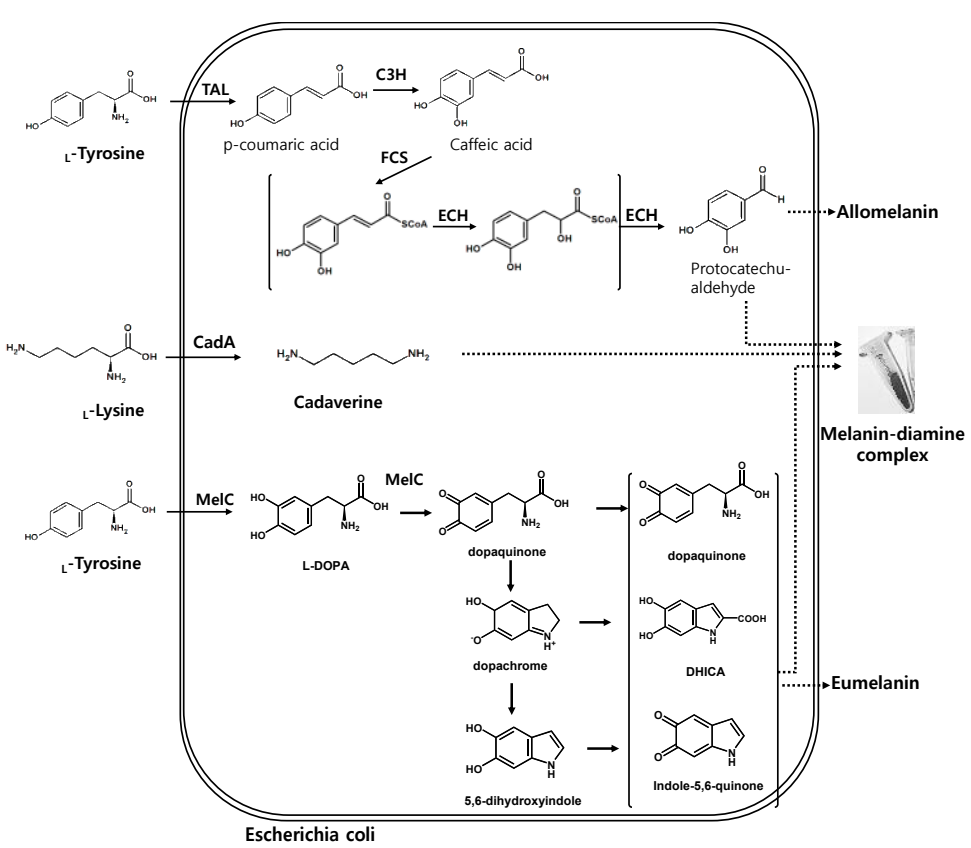

(B)

Figure 3. (A) Biosynthesis of the allomelanine-C5 diamine complex using E. coli cells expressing FCS and ECH enzymes, and production of the allomelanin-diamine complex from $5 \mathrm{mM}$ caffeic acid and diamine. (B) Co-production of the eumelanin-allomelanin-diamine complex by feeding L-tyrosine and L-lysine into E. coli cells expressing tyrosinase (MelC), tyrosine ammonia-lyase (TAL), C3H, FCS, ECH, and CadA simultaneously, respectively.

\subsection{Construction of a Synthetic Pathway for the Formation of the Melanin-Diamine Complex from L-Tyrosine and L-Lysine}

As caffeic acid and C5-diamine are platform chemicals that can be used in a variety of industries and can provide high added value, it is possible to supply L-tyrosine, and L-lysine amino acids as precursors instead. First, L-tyrosine was converted to caffeic acid through TAL and $\mathrm{C} 3 \mathrm{H}$ enzyme reaction, and L-lysine to C5-diamine through the CadA (lysine decarboxylase)-dependent decarboxylation reaction, respectively. Therefore, it was possible to produce caffeic acid-based allomelanin from L-tyrosine and L-lysine through a combination of TAL, C3H, FCS, ECH, and CadA enzyme reactions (Figure 3B).

Generally, eumelanin is an L-tyrosine-based pigment, where tyrosinase-dependent oxidation is responsible for its synthesis. The tyrosinase enzyme catalyzes the oxidation of L-tyrosine converting it into L-DOPA in an ortho-specific manner, followed by sequential oxidation of L-DOPA into dopaquinone which is further oxidized into dopaquinone radicals. These L-tyrosine-derived intermediates, dopaquinone, 5,6-dihydroxyindolecarboxylic acid (DHICA), and indole-5,6-quinone derived radicals, are polymerized randomly by each other, resulting in the formation of eumelanin polymer. This suggested that eumelanin could be produced simultaneously with allomelanin by expressing the tyrosinase MelC enzyme in the presence of L-tyrosine. Through the construction of the biosynthetic pathways of eumelanin and allomelanin together, biosynthesis of a novel melanin complex could be achieved through L-tyrosine and L-lysine co-biotransformation.

To co-produce the allomelanin, eumelanin, and diamine complex simultaneously in a single E. coli strain, each gene expressing TAL and C3H, FCS and ECH, and MelC and CadA were cloned in the pRSFDuet, pETDuet, and pACYCDuet vectors, respectively (Figure 4A). The expression of each of the six proteins in a single melanin-producing host strain was verified by SDS-PAGE analysis. It was confirmed that each protein with a molecular weight of TAL (76 kDa), FCS (69 kDa), ECH (30 kDa), MelC (32 kDa), and CadA (76 kDa) was well expressed as a soluble fraction and found at the corresponding molecular weight at SDS-PAGE (Figure 4B). 


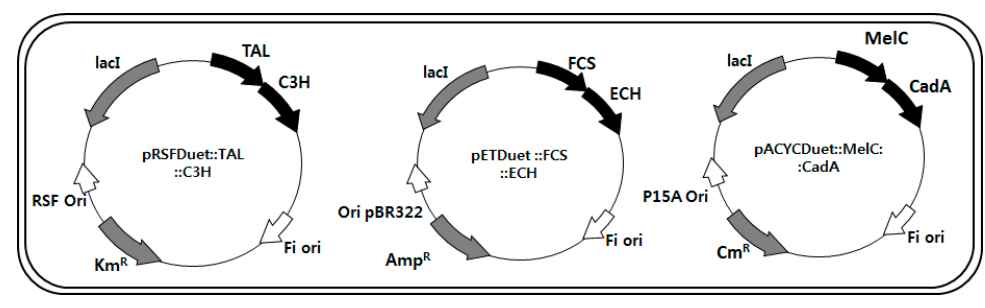

(A)

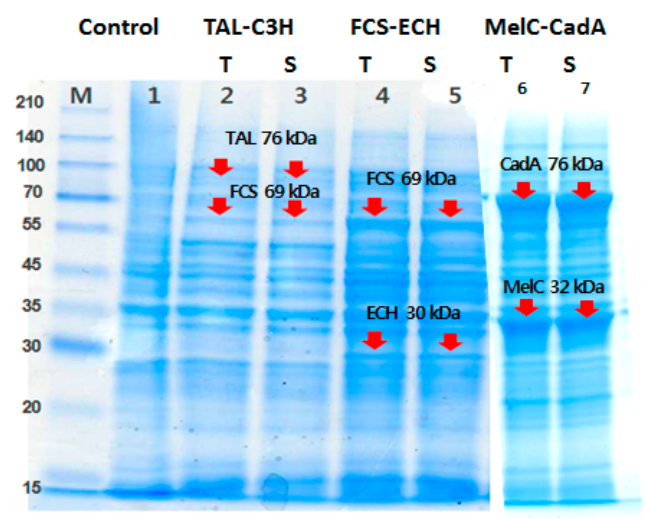

(B)

Figure 4. (A) Construction of TAL-C3H, FCS-ECH, and MelC-CadA co-expression plasmids. (B) SDS-PAGE analysis of TAL, C3H, FCS, ECH, MelC, and CadA enzyme co-expression in E. coli BL21(DE3). Control indicates E. coli BL21(DE3) cells without protein overexpression. Each $\mathrm{T}$ and $\mathrm{S}$ indicates the total and soluble fraction in each protein, respectively.

\subsection{Effect of TAL/C3H, FCS/ECH, and CadA Enzymes on the Production of the Melanin-Diamine Complex}

Quantitative analysis was performed on the generation of melanin-diamine complexes depending on the expression of TAL/C3H, FCS/ECH, and CadA enzymes in the melanin-producing $E$. coli host. When MelC was solely expressed with $5 \mathrm{mM}$ L-tyrosine, approximately $120 \mathrm{mg} / \mathrm{L}$ of melanin was produced (Figure 5A, Table 2 \#5). It seemed that only eumelanin was produced because allomelanin and diamine-producing enzymes and substrates were not supplied. On the other hand, when MelC and TAL/C3H were simultaneously expressed, approximately $370 \mathrm{mg} / \mathrm{L}$ of melanin was produced (Figure 5B, Table $2 \# 1)$. In this case, diamine was not supplied, but since the catechol of caffeic acid was supplied from L-tyrosine through the TAL/C3H enzyme reaction, it might have a positive effect on the production of the melanin complex.

Table 2. Production of melanin complexes by E. coli depending on the MelC, TAL/C3H, CadA, and FCS/ECH enzyme modules from L-tyrosine and L-lysine.

\begin{tabular}{ccccc}
\hline$\#$ & Overexpressed Enzymes & Melanin Unit & Substrate & Production (mg/L) \\
\hline 1 & TAL/C3H, MelC & Caffeic acid & L-tyrosine & $<370$ \\
2 & TAL/C3H, MelC, FCS, ECH & Protocatechualdehyde & L-tyrosine & $<140$ \\
3 & TAL/C3H, MelC, CadA & Caffeic acid & L-tyrosine, L-lysine & $<20$ \\
4 & TAL/C3H, MelC, CadA, FCS/ECH & Protocatechualdehyde & L-tyrosine, L-lysine & $<20$ \\
5 & MelC & L-DOPA & L-tyrosine & $<120$ \\
6 & MelC, FCS, ECH & L-DOPA & L-tyrosine & $<60$ \\
7 & MelC, CadA, FCS, ECH & L-DOPA & L-tyrosine, L-lysine & $<20$ \\
8 & MelC, CadA & L-DOPA & L-tyrosine, L-lysine & $<20$ \\
\hline
\end{tabular}

When $5 \mathrm{mM}$ tyrosine was supplied as a substrate while simultaneously expressing $\mathrm{TAL} / \mathrm{C} 3 \mathrm{H}, \mathrm{MelC}$, and FCS/ECH, the amount of melanin was reduced to $140 \mathrm{mg} / \mathrm{L}$ compared to when the FCS/ECH enzyme was not expressed (Figure 5D, Table 2\#2). The melanin complex was produced from the supply of eumelanin and protocatechualdehyde generated through the TAL/C3H-FCS/ECH enzyme reaction, but it might also be due to the low conversion activity resulting from the decrease in the amount of enzyme expression. In particular, when only MelC and FCS/ECH, excluding TAL/C3H, were expressed in the same reaction, the production of the melanin complex decreased dramatically to less than $60 \mathrm{mg} / \mathrm{L}$ (Figure 5C, Table 1 \#6). It could be possible to synthesize eumelanin from L-tyrosine via MelC expression; however, due to the simultaneous expression of the FCS/ECH enzyme, the level of MelC 
enzyme expression decreased and the conversion activity decreased accordingly. This could be due to unknown side reactions with intracellular metabolites.

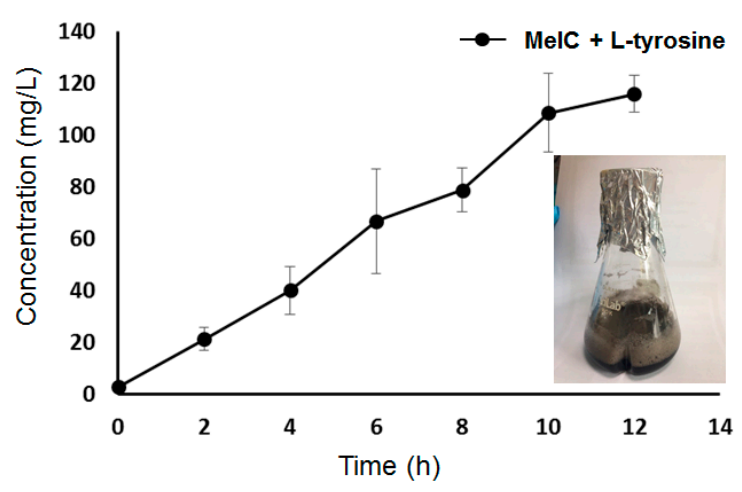

(A)

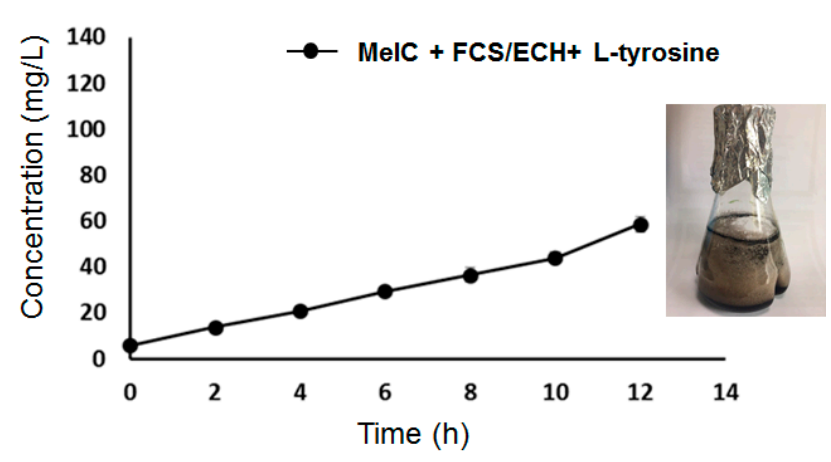

(C)

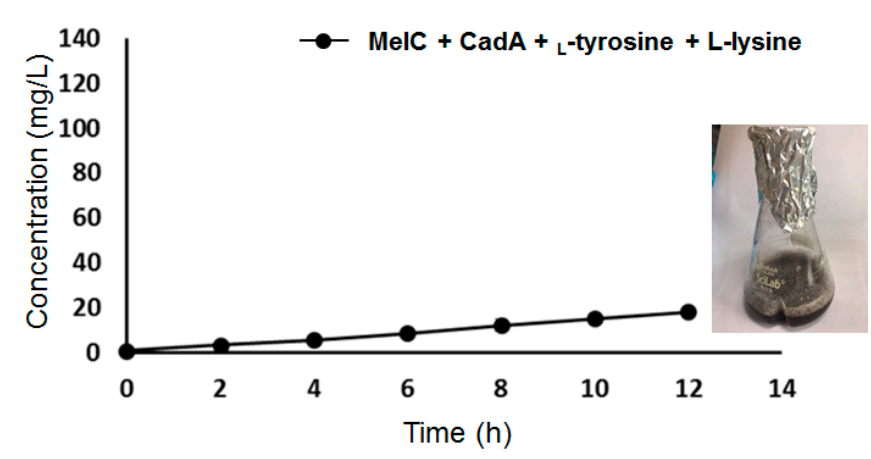

(E)

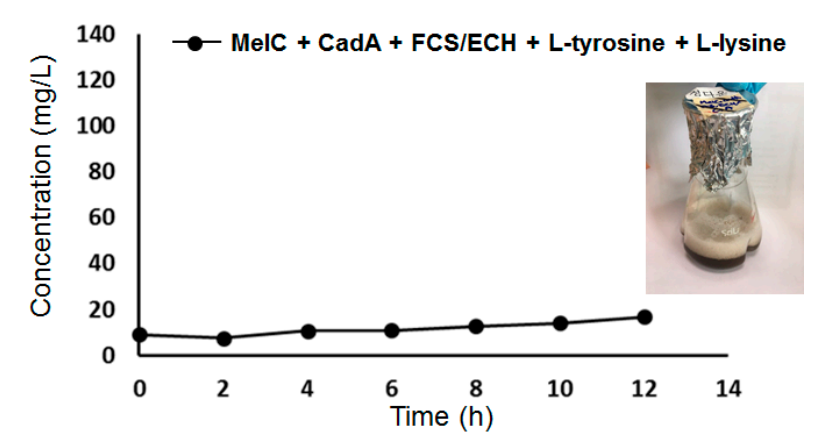

(G)

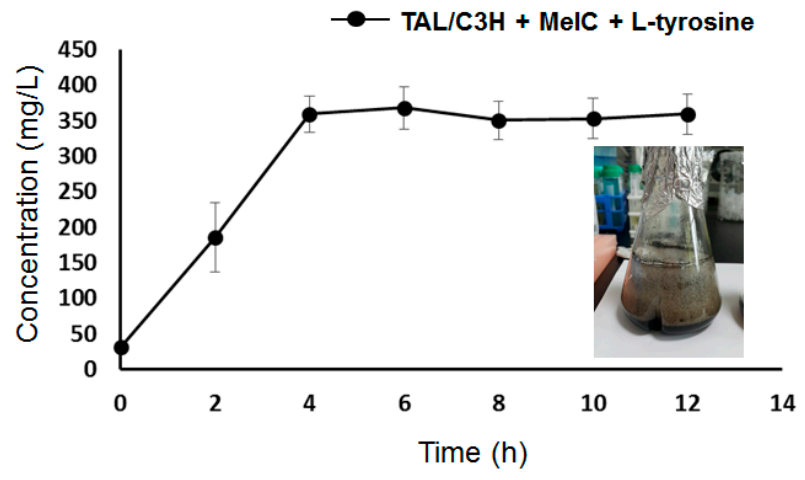

(B)

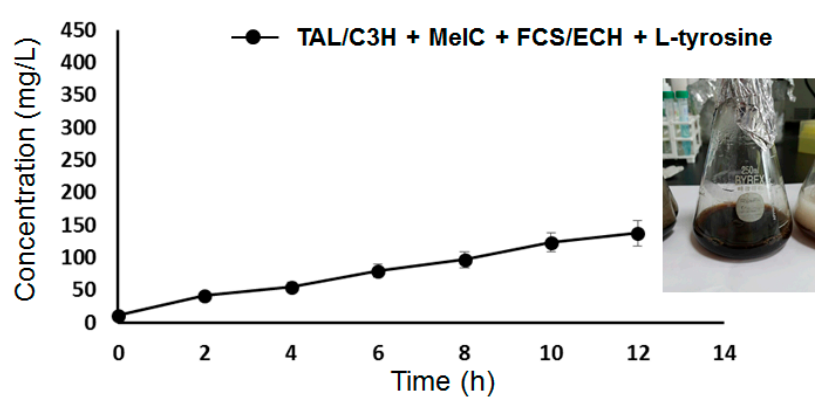

(D)

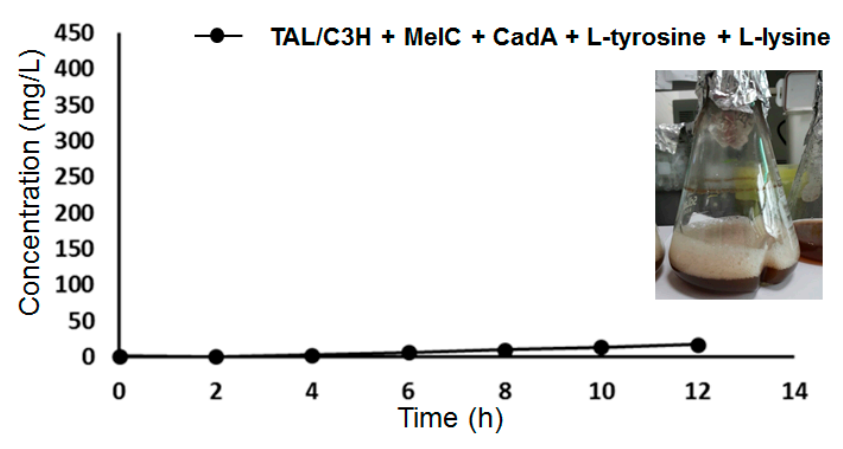

(F)

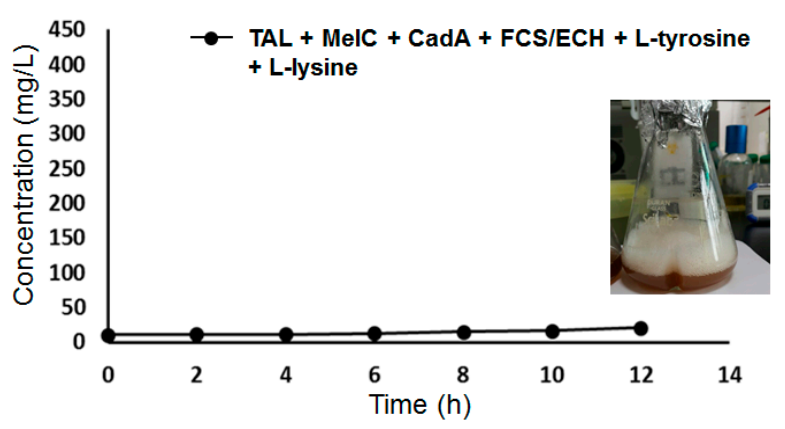

$(\mathbf{H})$

Figure 5. Eumelanin and melanin-diamine complex production profile in various enzyme expression levels. The detailed information of overexpressed enzymes in figure $(\mathbf{A}-\mathbf{H})$ and approximate titers are summarized in Table 2. 
In the case of allomelanin, diamine, and eumelanin co-production, all pathways from L-tyrosine, L-lysine, the six enzymes TAL/C3H, FCS/ECH, CadA, and MelC were expressed. When $5 \mathrm{mM}$ of L-tyrosine and L-lysine was supplied, the amount of melanin complex produced was approximately $20 \mathrm{mg} / \mathrm{L}$, or less (Figure $5 \mathrm{H}$, Table 1 \#4). This was a significantly lower production level compared to that obtained with the expression of MelC alone or that of MelC, TAL/C3H, and FCS/ECH without diamine supply. This could be because the expression level of melanin was remarkably reduced when the six enzymes were simultaneously expressed in a single host, or that the enzymatic conversion was remarkably decreased. In addition, the melanin complex production was also at a significantly low level (below $20 \mathrm{mg} / \mathrm{L}$ ) in strains concurrently expressing MelC and CadA (Figure 5E, Table 1 \#8), TAL/C3H (Figure 5F, Table 1 \#3), and FCS/ECH (Figure 5G, Table 1 \#7) enzymes.

Overall, simultaneous L-lysine supply and CadA expression led to low melanin complex production, at $20 \mathrm{mg} / \mathrm{L}$ or less. In addition to the low conversion activity, cytotoxicity due to C5-diamine formed by the CadA enzyme was also recorded. Recent studies have shown that E. coli resistance to C5-diamine is quite low. Exposure to $0.3-0.5 \mathrm{~mol} / \mathrm{L}$ C5-diamine for $8 \mathrm{~h}$ has been reported to induce rapid cell growth inhibition and cell disruption [36]. Therefore, further studies on intracellular diamine concentration control acting as a cross-linker for effective diamine supply and melanin complex formation are needed.

\subsection{Structural Analysis of Melanin Pigments}

To investigate the chemical structure of the synthesized melanin pigments ${ }^{1} \mathrm{H}$ NMR and FT-IR analysis was conducted first. ${ }^{1} \mathrm{H}-\mathrm{NMR}$ analysis resulted in similar patterns of chemical shifts between melanin standard as a control and synthetic melanin pigments (Figure S1). The melanin standard was commercial and prepared by tyrosine oxidation by hydrogen peroxide. In results, both showed obvious chemical shifts around 7.0-7.1 ppm originated from $\mathrm{Ph}-\mathrm{OH}$ of benzaldehyde and indole repeating unit. Also, several minor shifts were observed at aliphatic regions (0.8-1.3 ppm), which are not sufficient to interpret the chemical shift to structural correlation. On the other hand, FT-IR analysis showed characteristic wavenumber of 2850, and $2920 \mathrm{~cm}^{-1}$ in synthetic melanin pigments which were not observed in melanin standard and representative of $\mathrm{sp}^{2} \mathrm{C}-\mathrm{H}$ stretch (Figure $6 \mathrm{~b}-\mathrm{e}$ ). Instead, melanin standard showed wavenumber found in all melanin samples at 3420,1713,1623, and $1292 \mathrm{~cm}^{-1}$, which represented $\mathrm{N}-\mathrm{H}, \mathrm{C}=\mathrm{O}, \mathrm{C}=\mathrm{C}$, and $\mathrm{C}-\mathrm{N}$ stretch, respectively (Figure 6a). Interestingly, melanin synthesized by FCH/ECH expressing cells showed distinctive wavenumber at $1515-1520 \mathrm{~cm}^{-1}$, and melanin with additional diamine showed another one at $1440.9 \mathrm{~cm}^{-1}$, which represents $\mathrm{O}-\mathrm{C}=\mathrm{C}$ and $\mathrm{N}-\mathrm{C}=\mathrm{C}$ bonding, respectively (Figure $6 \mathrm{c}, \mathrm{d}$ ). Moreover, a unique wavenumber at $1440 \mathrm{~cm}^{-1}$ was observed only in diamine-containing melanin, which represented $-\mathrm{N}-\mathrm{C}=\mathrm{O}$ amide bonding (Figure 6e).

According to the previous report of caffeic acid esters with diamines, several representative components of MC/HMDA polymer were proposed, however, not the exact chemical structure was not fully elucidated yet [35]. Besides, several structural analyses by FT-ICR (Fourier-transform ion cyclotron resonance) mass spectrometry were performed in our previous study, however not enough information on the synthetic melanins could be obtained due to the complexity and difficulties in the analysis [17]. To achieve perfect understandings of melanin structure and structure-functionality correlation, further in-depth investigation would be necessary. 


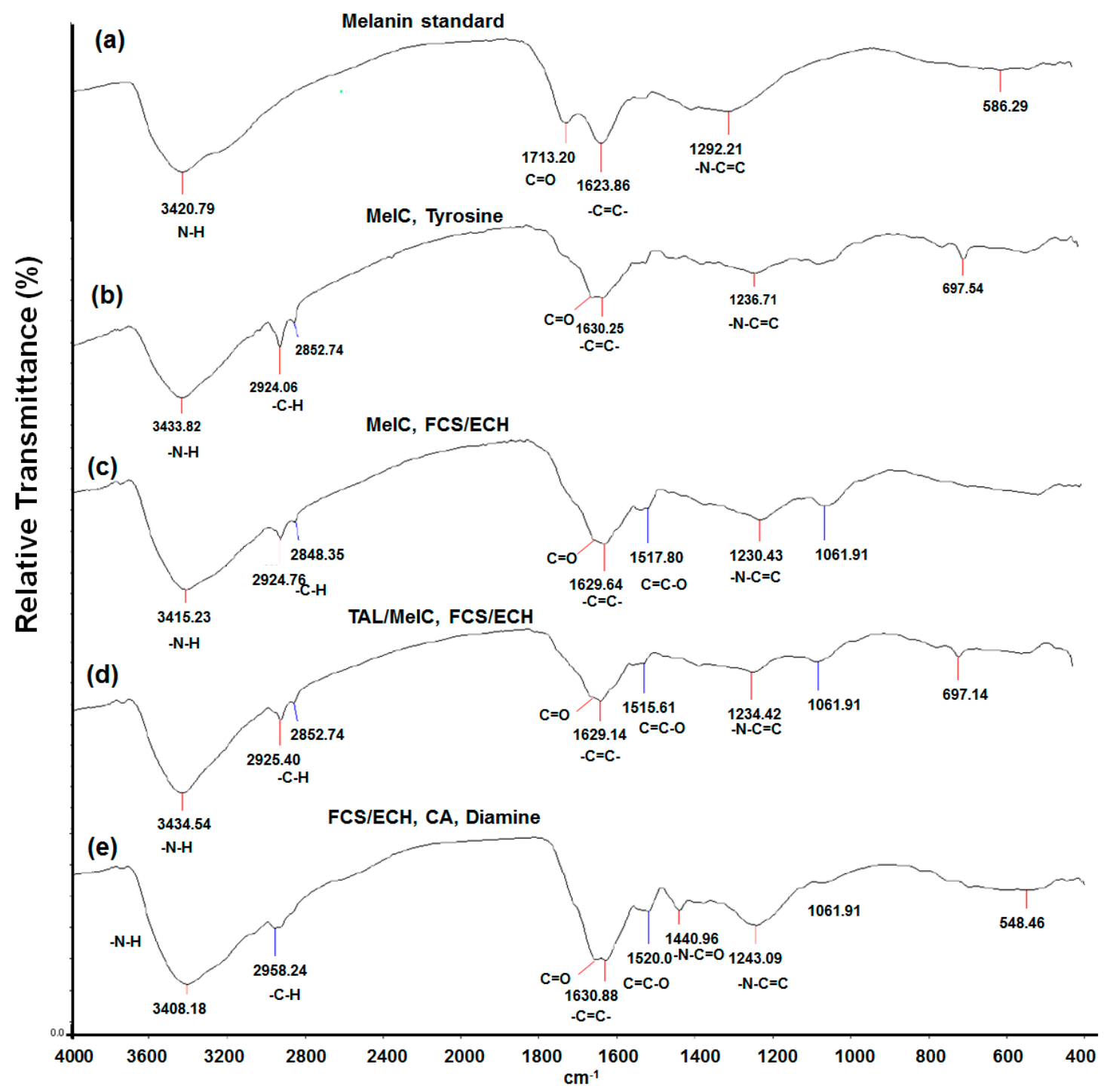

Figure 6. IR spectra of (a) commercial melanin as a control, (b) MelC, tyrosine, (c) MelC, FCS/ECH, and tyrosine, (d) TAL/MelC, FCS/ECH, and (e) FCS/ECH, caffeic acid, and diamine.

\section{Discussion}

In this study, caffeic acid-based synthetic melanin pigments were synthesized using wild-type S. glaucescens and recombinant E. coli strains from caffeic acid or the amino acids L-tyrosine and L-lysine. The synthesized melanin by S. glaucescens was further investigated for its functionalities, such as ABTS radical scavenging capacity and dyeing performance. Interestingly, an additional supply of laccase enzyme into dyeing performance positively affected the dyeing performances by leading to the oxidation of melanin and polymerization.

However, the use of S. glaucescens for melanin production, next recombinant E. coli strains with additional linker supplement were utilized and investigated for their melanin production. Besides, the supply of C5-diamine, which was reported to lead to more complex crosslinking between melanin units, to caffeic acid-based melanin synthesis was also investigated for higher production and novel functionalities. First, the supply of C5diamine increased the melanin production titer in the recombinant $E$. coli system expressing FCS and ECH enzymes. Next, for the further development of diamine, eumelanin, and allomelanin complex synthesis, expression of several combinations of enzymes responsible for melanin monomer and linker supply were investigated, followed by quantifying the melanin produced. Based on the results of this study, the potential to use melanin pigments 
synthesized from microorganisms as functional dyeing materials was confirmed. In terms of titer, the TAL/C3H and MelC combination, with a supply of L-tyrosine showed the highest melanin production of approximately $400 \mathrm{mg} / \mathrm{L}$.

In recent years, environmental pollution and ecosystem destruction due to the discharge of textile dyes to aquatic ecosystems have been observed. From this point of view, it is expected that fastness can be improved through laccase enzyme treatment during the dyeing process and that dyeing efficiency can be improved through the introduction of a continuous dyeing cycle to develop an eco-friendly process throughout the dyeing cycle. Besides, melanin is a promising biomaterial that could be used for different purposes. It would be possible to use melanin-diamine complexes as functional films and coating materials, after the characterization of the physical properties of melanin-diamine composite polymers in the future. Although its chemical structure and structure-functionalities are not yet fully understood, engineering studies to obtain desirable production titers and novel functionalities of biomaterial melanin complexes would be very promising further studies.

\section{Materials and Methods}

\subsection{Strains and Chemicals}

The Streptomyces glaucescens KCTC988 strain used in the experiment was purchased from the Center for Biological Resources (KCTC, Korean Collection for Type Cultures). E. coli DH5 $\alpha$ and E. coli BL21 (DE3) were used to construct plasmids. Burkholderia glumae BGR1 strain was purchased from the Korean Collection for Type Cultures (KCTC). L-tyrosine, L-lysine, caffeic acid, diaminopentane (cadaverine), isopropyl $\beta$-D-1-thiogalactopyranoside (IPTG) used for melanin synthesis, and Melanin standard (Cas. 8049-97-6) were all purchased from SigmaAldrich Korea (Suwon, Gyeonggido, Korea).

\subsection{Construction of Expression Plasmids of TAL-C3H, FCS-ECH, and MelC-CadA Coding Genes}

Genes encoding TAL and C3H enzymes derived from Rhodotorula glutinis and Saccharothrix espanaensis strains were synthesized by optimizing them based on codon usage (Bioneer, Daejeon, Korea). The TAL and C3H coding genes amplified via PCR were cloned into the multi-cloning site (MCS) of the pRSFduet-1 vector. The genes encoding FCS and ECH enzymes were derived from the B. glumae BGR1 strain, and the genes obtained through PCR from the B. glumae BGR1 genome were cloned into the MCS of the pETDuet-1 vector, respectively [18]. Also, the genes encoding MelC and CadA were derived from Bacillus megaterium and Klebsiella pneumoniae strains, respectively, and the genes amplified by PCR were cloned into the MCS of the pACYCDuet-1 vector [37].

\subsection{Cell Culture, Protein Expression, and SDS-PAGE Analysis}

The culture medium for $S$. glaucescens was composed of glycerol $15 \mathrm{~g} / \mathrm{L}$, L-asparagine $0.5 \mathrm{~g} / \mathrm{L}, \mathrm{K}_{2} \mathrm{HPO}_{4} 0.5 \mathrm{~g} / \mathrm{L}, \mathrm{MgSO}_{4} \cdot 7 \mathrm{H}_{2} \mathrm{O} 0.5 \mathrm{~g} / \mathrm{L}$, and $\mathrm{FeSO}_{4} \cdot 7 \mathrm{H}_{2} \mathrm{O} 0.01 \mathrm{~g} / \mathrm{L}$ [7]. For melanin production, $5 \mathrm{mM}$ caffeic acid was added to the culture medium. After $2 \mathrm{~mL}$ of the initial culture solution was incubated at $30^{\circ} \mathrm{C}$ for $2-3$ days, $0.1 \%(v / v)$ was inoculated into $50 \mathrm{~mL}$ fresh culture medium and incubated at $30^{\circ} \mathrm{C}$. Cultures were incubated while checking the cell growth and melanin production up to $144 \mathrm{~h}$ after inoculation. A 1-mL sample of the culture was collected every $24 \mathrm{~h}$ and used for the quantitative analysis of melanin.

E. coli BL21(DE3) harboring both pETDuet::fcs::ech-pRSFDuet::tal::c3h and pACYCDuet::melC::cadA plasmids were cultured as follows. After incubating $2 \mathrm{~mL}$ of the initial Luria-Bertani (LB) medium at $37^{\circ} \mathrm{C}$ for $24 \mathrm{~h}, 0.1 \%(v / v)$ was inoculated into $50 \mathrm{~mL}$ of fresh $\mathrm{LB}$ medium and incubated at $37^{\circ} \mathrm{C}$. When the $\mathrm{OD}_{600}$ reached $0.8,0.1 \mathrm{mM} \mathrm{IPTG}$ was injected into the culture medium so the expression of the protein regulated by the $\mathrm{T} 7$ promoter was induced. Then, the incubation temperature was lowered to $30^{\circ} \mathrm{C}$ and the cultures were incubated for an additional $12 \mathrm{~h}$. Next, SDS-PAGE analysis was performed to confirm protein expression under the different growth conditions. After incubation, the cultures were centrifuged for $10 \mathrm{~min}$ at 13,200 rpm. The supernatant was discarded, and the cells were washed twice with $20 \mathrm{~mL}$ of phosphate-buffered saline (PBS) and resuspended in 10 
$\mathrm{mL}$ sonication buffer. For SDS-PAGE analysis, $1.5 \mathrm{~mL}$ of the cell solution was sonicated to disrupt the cells, and the total protein fraction and the soluble fraction obtained after centrifugation at 13,200 rpm for $20 \mathrm{~min}$ were used for SDS-PAGE analysis. At this time, wild-type E. coli BL21 (DE3) cells were subjected to the same procedure to obtain the total and soluble fractions and used as the SDS-PAGE control.

\subsection{Bioproduction of Melanin through the Whole Cell Biotransformation of Substrates}

E. coli BL21(DE3) strains containing or all of pETDuet::fcs::ech, pRSFDuet::tal::c3h, pACYCDuet::melC::i plasmid, expressed proteins according to the aforementioned method. For the whole cell reaction, caffeic acid, L-tyrosine, and L-lysine were injected into the reaction solution to a final concentration of $5 \mathrm{mM}$, after resuspension in $10 \mathrm{~mL} \mathrm{M9} \mathrm{minimal} \mathrm{medium.} \mathrm{The}$ whole cell reaction was further cultured for at least $12 \mathrm{~h}$ more while confirming the melanin production of each culture sample incubating with shaking at $200 \mathrm{rpm}$ at $30^{\circ} \mathrm{C}$.

\subsection{Extraction and Quantification of Melanin}

After the addition of $5 \mathrm{mM}$ caffeic acid, the samples for each period were centrifuged at $5000 \times g$ for $15 \mathrm{~min}$ to separate the supernatant. $\mathrm{HCl}(6 \mathrm{M})$ was added to the supernatant to adjust the $\mathrm{pH}$ to 2 and then allowed to stand at room temperature for $4 \mathrm{~h}$ to precipitate. After precipitation of the melanin sample, the precipitated melanin was separated via centrifugation at $9000 \times g$ for $15 \mathrm{~min}$. The extracted melanin was washed three times with purified water, centrifuged, and dried at $60^{\circ} \mathrm{C}$ for $24 \mathrm{~h}$ to obtain granular melanin. Melanin was quantitatively analyzed by measuring the weight of melanin obtained in the dry state.

During the whole-cell reaction, samples at each time point were centrifuged at $5000 \times g$ for $15 \mathrm{~min}$, and the supernatants were treated with $6 \mathrm{M} \mathrm{HCl}$ to lower the $\mathrm{pH}$ to 2 and precipitate melanin. After precipitation of the melanin sample for $4 \mathrm{~h}$, the precipitated melanin was separated via centrifugation at $9000 \times g$ for $15 \mathrm{~min}[17,18]$. The extracted melanin was washed three times with purified water and dried at $60{ }^{\circ} \mathrm{C}$ for $24 \mathrm{~h}$. The produced melanin was quantitatively analyzed by measuring the absorbance at an optical density (OD) of $400 \mathrm{~nm}$. After the whole cell reaction, the cells were separated via centrifugation at 13,200 rpm for $10 \mathrm{~min}$, and the supernatant was used for the quantitative analysis of melanin. Melanin was quantified by applying a conversion constant of $0.066 \mathrm{~g} / \mathrm{L}$ per unit of $\mathrm{OD}_{400}[17,18]$. The characteristic and structural features of synthetic melanins were analyzed by ${ }^{1} \mathrm{H}$ NMR and Fourier-transformed Infrared (FT-IR) analysis.

\subsection{Determination of the ABTS Radical Scavenging Capacity of Melanin}

To evaluate the radical removal performance of melanin, dried melanin was dissolved in $5 \% \mathrm{NaOH}$ and prepared as a $1 \mathrm{~g} / \mathrm{L}$ solution. The reaction solution was prepared by mixing an ABTS solution diluted at a concentration of $8.12 \mathrm{mg} / \mathrm{mL}$ in phosphate-buffered saline (PBS) with an aqueous solution of $\mathrm{K}_{2} \mathrm{~S}_{2} \mathrm{O}_{8}$ at a concentration of $1.32 \mathrm{mg} / \mathrm{mL}$ at 1:1 [17,18]. After mixing, the $\mathrm{pH}$ was adjusted to 7.4 , and the reaction was started by adding melanin at concentrations of 5,10 , and $20 \mathrm{mg} / \mathrm{L}$ to the reaction solution. The reaction was carried out at $25^{\circ} \mathrm{C}$ for $24 \mathrm{~h}$ while blocking sunlight. After completion of the reaction, the aqueous reaction solution was diluted by adjusting the absorbance to 0.7 , and the absorbance was measured at $734 \mathrm{~nm}$ to determine ABTS radical scavenging capacity through the equation $[(\mathrm{B}-\mathrm{S}) / \mathrm{B}] \times 100(\%)$, where $\mathrm{B}$ is the absorbance of $\mathrm{ABTS}$ and $\mathrm{S}$ is the absorbance of the sample + ABTS [38].

\subsection{Fabric Dyeing Using Melanin}

The melanin obtained in a dry state was subjected to a dyeing performance test on cotton fibers. When dyeing directly using the culture medium, cotton fibers were added to $50 \mathrm{~mL}$ of the culture supernatant separated through centrifugation, and the reaction was performed at $50{ }^{\circ} \mathrm{C}$ for $2 \mathrm{~h}$. An aqueous melanin solution at a concentration of $125 \mathrm{mg} / \mathrm{L}$ was used for dyeing. To confirm the effect of copper ions during dyeing, $1 \mathrm{mg} \mathrm{CuSO} 4$ was added before the start of the reaction. To evaluate the staining effect after the addition of 
the laccase enzyme, $1.5 \mathrm{U}$ of the laccase enzyme $(0.5 \mathrm{U} / \mathrm{mg})$ derived from Trametes versicolor was added to the melanin solution, followed by staining. After dyeing, the cotton fibers were dried at $60^{\circ} \mathrm{C}$ for $24 \mathrm{~h}$.

\subsection{Color Difference Test and Determination of Dyeing Fastness to Evaluate Dyeing Performance}

To evaluate the dyeing performance, the fibers were washed two to three times with purified water and then dried in the same manner. For efficient dyeing, two cycles of dyeing, drying, and washing were performed using the melanin supernatant. The color difference of the cotton after dyeing was measured using a Colorimeter JZ-600 instrument (Shenzhen Kingwell Instrument Co., Ltd., Guangdong, China) and it's Color Analysis Management Software [17]. Also, the fastness using the color difference before and after dyeing was calculated as $100+\left[\left(\mathrm{L}+\mathrm{L}^{\prime}\right) / \mathrm{L}\right] \times 100(\%)$, where $\mathrm{L}$ is the brightness before washing, $\mathrm{L}^{\prime}$ is the brightness determined after washing, and the fastness of melanin staining was calculated based on $100 \%$ when there was no color difference.

Supplementary Materials: The following are available online at https:/ / www.mdpi.com/1422-006 $7 / 22 / 5 / 2413 / s 1$.

Author Contributions: Conceptualization, K.-Y.C.; validation, S.-Y.A., P.D.V.N.S., and S.J.; investigation, S.-Y.A. and S.J.; writing-original draft preparation, S.-Y.A. and S.J; writing-review and editing, K.-Y.C.; supervision, K.-Y.C. All authors have read and agreed to the published version of the manuscript.

Funding: This research was funded by the Ajou University Research Fund.

Institutional Review Board Statement: Not applicable.

Informed Consent Statement: Not applicable.

Data Availability Statement: Data supporting reported results will be provided upon request.

Conflicts of Interest: The authors declare no conflict of interest.

\section{References}

1. Nosanchuk, J.D.; Stark, R.E.; Casadevall, A. Fungal Melanin: What do We Know About Structure? Front. Microbiol. 2015, 6, 1463. [CrossRef] [PubMed]

2. Simon, J.D.; Rozanowska, M. Perspectives on the structure and function of melanin. Pigment. Cell Melanoma Res. 2008, 21, 346-347. [CrossRef]

3. Powell, B.J.; Baruah, T.; Bernstein, N.; Brake, K.; McKenzie, R.H.; Meredith, P.; Pederson, M.R. A first-principles density-functional calculation of the electronic and vibrational structure of the key melanin monomers. J. Chem. Phys. 2004, 120, 8608-8615. [CrossRef] [PubMed]

4. Rodríguez-Martínez, S.; Wakamatsu, K.; Galván, I. Increase of the benzothiazole moiety content of pheomelanin pigment after endogenous free radical inducement. Dyes Pigment. 2020, 180, 108516. [CrossRef]

5. Varga, M.; Berkesi, O.; Darula, Z.; May, N.V.; Palagyi, A. Structural characterization of allomelanin from black oat. Phytochemistry 2016, 130, 313-320. [CrossRef] [PubMed]

6. Kuzumaki, T.; Matsuda, A.; Wakamatsu, K.; Ito, S.; Ishikawa, K. Eumelanin biosynthesis is regulated by coordinate expression of tyrosinase and tyrosinase-related protein-1 genes. Exp. Cell Res. 1993, 207, 33-40. [CrossRef] [PubMed]

7. El-Naggar, N.E.; El-Ewasy, S.M. Bioproduction, characterization, anticancer and antioxidant activities of extracellular melanin pigment produced by newly isolated microbial cell factories Streptomyces glaucescens NEAE-H. Sci. Rep. 2017, 7, 42129. [CrossRef]

8. Gessler, N.N.; Egorova, A.S.; Belozerskaia, T.A. Melanin pigments of fungi under extreme environmental conditions (review). Prikl. Biokhimiia Mikrobiol. 2014, 50, 125-134.

9. Prateeksha; Bajpai, R.; Yusuf, M.A.; Upreti, D.K.; Gupta, V.K.; Singh, B.N. Endolichenic fungus, Aspergillus quandricinctus of Usnea longissima inhibits quorum sensing and biofilm formation of Pseudomonas aeruginosa PAO1. Microb. Pathog. 2020, 140, 103933. [CrossRef]

10. Perez-Cuesta, U.; Aparicio-Fernandez, L.; Guruceaga, X.; Martin-Souto, L.; Abad-Diaz-de-Cerio, A.; Antoran, A.; Buldain, I.; Hernando, F.L.; Ramirez-Garcia, A.; Rementeria, A. Melanin and pyomelanin in Aspergillus fumigatus: From its genetics to host interaction. Int. Microbiol. 2020, 23, 55-63. [CrossRef]

11. Ribera, J.; Panzarasa, G.; Stobbe, A.; Osypova, A.; Rupper, P.; Klose, D.; Schwarze, F. Scalable Biosynthesis of Melanin by the Basidiomycete Armillaria cepistipes. J. Agric. food Chem. 2019, 67, 132-139. [CrossRef] 
12. Pearce, M.H. In vitro interactions between Armillaria luteobubalina and other wood decay fungi. Mycol. Res. 1990, 94, 753-761. [CrossRef]

13. Ganesh Kumar, C.; Sahu, N.; Narender Reddy, G.; Prasad, R.B.; Nagesh, N.; Kamal, A. Production of melanin pigment from Pseudomonas stutzeri isolated from red seaweed Hypnea musciformis. Lett. Appl. Microbiol. 2013, 57, 295-302. [CrossRef]

14. Fairhead, M.; Thöny-Meyer, L. Bacterial tyrosinases: Old enzymes with new relevance to biotechnology. New Biotechnol. 2012, 29, 183-191. [CrossRef]

15. Faccio, G.; Kruus, K.; Saloheimo, M.; Thöny-Meyer, L. Bacterial tyrosinases and their applications. Process. Biochem. 2012, 47, 1749-1760. [CrossRef]

16. Min, K.; Park, G.W.; Yoo, Y.J.; Lee, J.-S. A perspective on the biotechnological applications of the versatile tyrosinase. Bioresour. Technol. 2019, 289, 121730. [CrossRef] [PubMed]

17. Ahn, S.-Y.; Choi, M.; Jeong, D.-w.; Park, S.; Park, H.; Jang, K.-S.; Choi, K.-Y. Synthesis and chemical composition analysis of protocatechualdehyde-based novel melanin dye by 15T FT-ICR: High dyeing performance on soft contact lens. Dyes Pigment. 2019, 160, 546-554. [CrossRef]

18. Jang, S.; Gang, H.; Kim, B.-G.; Choi, K.-Y. FCS and ECH dependent production of phenolic aldehyde and melanin pigment from 1-tyrosine in Escherichia coli. Enzym. Microb. Tech. 2018, 112, 59-64. [CrossRef]

19. Seo, D.; Choi, K.-Y. Heterologous production of pyomelanin biopolymer using 4-hydroxyphenylpyruvate dioxygenase isolated from Ralstonia pickettii in Escherichia coli. Biochem. Eng. J. 2020, 157, 107548. [CrossRef]

20. Namgung, S.; Park, H.A.; Kim, J.; Lee, P.-G.; Kim, B.-G.; Yang, Y.-H.; Choi, K.-Y. Ecofriendly one-pot biosynthesis of indigo derivative dyes using CYP102G4 and PrnA halogenase. Dyes Pigment. 2019, 162, 80-88. [CrossRef]

21. Serpentini, C.-L.; Gauchet, C.; de Montauzon, D.; Comtat, M.; Ginestar, J.; Paillous, N. First electrochemical investigation of the redox properties of DOPA-melanins by means of a carbon paste electrode. Electrochim. Acta 2000, 45, 1663-1668. [CrossRef]

22. Madkhali, N.; Alqahtani, H.R.; Alterary, S.; Albrithen, H.A.; Laref, A.; Hassib, A. Characterization and electrochemical deposition of natural melanin thin films. Arab. J. Chem. 2020, 13, 4987-4993. [CrossRef]

23. Robinson, G.M.; Iwuoha, E.I.; Smyth, M.R. Characterisation of electrosynthetic l-dopa-melanin films by electrochemical and spectroelectrochemical techniques. Electrochim. Acta 1998, 43, 3489-3496. [CrossRef]

24. Liu, Y.; Yu, Z.; Zhang, Y.; Qi, C.; Tang, R.; Zhao, B.; Wang, H.; Han, Y. Microbial dyeing-Infection behavior and influence of Lasiodiplodia theobromae in poplar veneer. Dyes Pigment. 2020, 173, 107988. [CrossRef]

25. Caldas, M.; Santos, A.C.; Veiga, F.; Rebelo, R.; Reis, R.L.; Correlo, V.M. Melanin nanoparticles as a promising tool for biomedical applications-A review. Acta Biomater. 2020, 105, 26-43. [CrossRef]

26. Hong, Z.-Y.; Feng, H.-Y.; Bu, L.-H. Melanin-based nanomaterials: The promising nanoplatforms for cancer diagnosis and therapy. Nanomed. Nanotechnol. Biol. Med. 2020, 28, 102211. [CrossRef] [PubMed]

27. Bhatia, S.K.; Kim, Y.H.; Kim, H.J.; Seo, H.M.; Kim, J.H.; Song, H.S.; Sathiyanarayanan, G.; Park, S.H.; Park, K.; Yang, Y.H. Biotransformation of lysine into cadaverine using barium alginate-immobilized Escherichia coli overexpressing CadA. Bioprocess. Biosyst. Eng. 2015, 38, 2315-2322. [CrossRef]

28. Hua, Y.; Ma, C.; Wei, T.; Zhang, L.; Shen, J. Collagen/Chitosan Complexes: Preparation, Antioxidant Activity, Tyrosinase Inhibition Activity, and Melanin Synthesis. Int. J. Mol. Sci. 2020, 21, 313. [CrossRef] [PubMed]

29. Yao, Z.Y.; Qi, J.H. Comparison of Antioxidant Activities of Melanin Fractions from Chestnut Shell. Molecules 2016, 21, 487. [CrossRef]

30. Liberti, D.; Alfieri, M.L.; Monti, D.M.; Panzella, L.; Napolitano, A. A Melanin-Related Phenolic Polymer with Potent Photoprotective and Antioxidant Activities for Dermo-Cosmetic Applications. Antioxidants 2020, 9, 270. [CrossRef]

31. Ma, Y.P.; Bao, Y.H.; Kong, X.H.; Tian, J.J.; Han, B.; Zhang, J.C.; Chen, X.J.; Zhang, P.Q.; Wang, H.; Dai, X.D.; et al. Optimization of Melanin Extraction from the Wood Ear Medicinal Mushroom, Auricularia auricula-judae (Agaricomycetes), by Response Surface Methodology and Its Antioxidant Activities In Vitro. Int. J. Med. Mushrooms 2018, 20, 1087-1095. [CrossRef] [PubMed]

32. Jia, W.; Wang, Q.; Fan, X.; Dong, A.; Yu, Y.; Wang, P. Laccase-mediated in situ oxidation of dopa for bio-inspired coloration of silk fabric. RSC Adv. 2017, 7, 12977-12983. [CrossRef]

33. Eisenman, H.C.; Mues, M.; Weber, S.E.; Frases, S.; Chaskes, S.; Gerfen, G.; Casadevall, A. Cryptococcus neoformans laccase catalyses melanin synthesis from both D- and L-DOPA. Microbiology 2007, 153, 3954-3962. [CrossRef]

34. Figueroa-Espinoza, M.C.; Rouau, X. Effect of cysteinyl caffeic acid, caffeic acid, and L-dopa on the oxidative cross-linking of feruloylated arabinoxylans by a fungal laccase. J. Agric. Food Chem. 1999, 47, 497-503. [CrossRef] [PubMed]

35. Iacomino, M.; Paez, J.I.; Avolio, R.; Carpentieri, A.; Panzella, L.; Falco, G.; Pizzo, E.; Errico, M.E.; Napolitano, A.; del Campo, A.; et al. Multifunctional Thin Films and Coatings from Caffeic Acid and a Cross-Linking Diamine. Langmuir ACS J. Surf. Colloids 2017, 33, 2096-2102. [CrossRef] [PubMed]

36. Qian, Z.G.; Xia, X.X.; Lee, S.Y. Metabolic engineering of Escherichia coli for the production of cadaverine: A five carbon diamine. Biotechnol. Bioeng. 2011, 108, 93-103. [CrossRef]

37. Kim, J.; Seo, H.-M.; Bhatia, S.K.; Song, H.-S.; Kim, J.-H.; Jeon, J.-M.; Choi, K.-Y.; Kim, W.; Yoon, J.-J.; Kim, Y.-G.; et al. Production of itaconate by whole-cell bioconversion of citrate mediated by expression of multiple cis-aconitate decarboxylase (cadA) genes in Escherichia coli. Sci. Rep. 2017, 7, 1-9. [CrossRef]

38. Re, R.; Pellegrini, N.; Proteggente, A.; Pannala, A.; Yang, M.; Rice-Evans, C. Antioxidant activity applying an improved ABTS radical cation decolorization assay. Free Radic. Biol. Med. 1999, 26, 1231-1237. [CrossRef] 